\title{
From Digital Divide to Information Availability: A Wi-Fi-Based Novel Solution for Information Dissemination
}

\author{
Muhammad Faran Majeed (D), ${ }^{1}$ Irshad Ahmed Abbasi $(\mathbb{D}),{ }^{2}$ Sikandar Ali $\left(\mathbb{D},{ }^{3,4}\right.$ \\ Elfatih Elmubarak Mustafa, ${ }^{2}$ Ibrar Hussain, ${ }^{1}$ Khalid Saeed $\left(\mathbb{D},{ }^{1}\right.$ Muhammad Faisal Abrar, ${ }^{5}$ \\ Mah E. No, ${ }^{6}$ and Muhammad Kashif Khattak (iD) ${ }^{7}$ \\ ${ }^{1}$ Department of Computer Science, Shaheed Benazir Bhutto University, Sheringal, Dir (U), Khyber Pakhtunkhwa, Pakistan \\ ${ }^{2}$ Department of Computer Science, Faculty of Science and Arts at Belgarn, University of Bisha, P.O. Box 60, \\ Sabt Al-Alaya 61985, Saudi Arabia \\ ${ }^{3}$ Department of Computer Science and Technology, China University of Petroleum-Beijing, Beijing 102249, China \\ ${ }^{4}$ Beijing Key Lab of Petroleum Data Mining, China University of Petroleum-Beijing, Beijing 102249, China \\ ${ }^{5}$ Department of Computer Science, University of Engineering \& Technology, Mardan, Khyber Pakhtunkhwa, Pakistan \\ ${ }^{6}$ Department of Computer Science, CECOS University of IT \& Emerging Sciences, Peshawar, Khyber Pakhtunkhwa, Pakistan \\ ${ }^{7}$ Southern Punjab Redeemers College, Taunsa Shareef, Punjab, Pakistan
}

Correspondence should be addressed to Sikandar Ali; sikandar@cup.edu.cn

Received 31 December 2020; Revised 27 January 2021; Accepted 10 February 2021; Published 28 February 2021

Academic Editor: Mohammad Hossein Anisi

Copyright (c) 2021 Muhammad Faran Majeed et al. This is an open access article distributed under the Creative Commons Attribution License, which permits unrestricted use, distribution, and reproduction in any medium, provided the original work is properly cited.

\begin{abstract}
Digital divide means unequal access to the people for information and communication technology (ICT) facilities. The developed countries are comparatively less digitally divided as compared to developing countries. This study focuses on District Chitral considering its geographical conditions and high mountainous topography which plays a significant role in its isolation. Aside from the digital divide, the situation in Chitral is even more severe in terms of the absence of basic ICT infrastructure and electricity in the schools. To address this issue, especially in female secondary and higher secondary schools, we designed a project to bridge the digital divide via Wireless Local Area Network on Raspberry Pi3 for balancing the ICT facilities in the targeted area. The Wi-Fi-Based Content Distributors (Wi-Fi-BCDs) were provided to bridge the digital divide in rural area schools of Chitral. The Wi-Fi-BCD is a solar-based system that is used to deliver quality educational contents directly to classroom, library, or other learning environments without electricity connection and Internet wire as these facilities are available by default in it. The close-ended questionnaire was adopted to collect data from the students, teachers, and headmistresses of girl secondary and higher secondary schools in Chitral. The procedure of validity, reliability, regression, correlation, and exploratory factor analysis was used to analyze the obtained data. The technology acceptance model (TAM) was modified and adopted to examine the effects of Wi-Fi-BCD for bridging the digital divide. The relationship of the modified TAM model was examined through regression and correlation to verify the model fitness according to the data obtained. The result analysis of this study shows that the relationship of the modified TAM model with its variables is positively significant, while the analysis of path relationship between model variables and outcomes from the questionnaire shows that it motivates learners to use Wi-Fi-BCD.
\end{abstract}

\section{Introduction}

In this section, we discuss the background of the study, ICT, its role, ICT education for girls in Pakistan, digital divide, and its effects.
1.1. Background of the Study. The limited access to the Internet is the main reason for the huge digital divide in the rural areas of Pakistan. This digital divide is quite visible in the case of female students. The major objective of this study, therefore, is to bridge this gap and provide accessibility through 
Wi-Fi-BCD along with tablet computers to enable the female students to get benefits from the technology offered.

Our study focused on District Chitral. Chitral is surrounded by Dir (upper) in its South and connected via Lawari Pass $(10,500 \mathrm{ft})$ and Gilgit in the North via Shandoor Pass $(12,201 \mathrm{ft})$. Both routes to Chitral are closed due to snowfall during winter making it almost impossible to reach the city. The geographical conditions and high mountainous topography of the district play a significant role in its isolation. Aside from the digital divide, the situation in Chitral is even more severe in terms of the absence of basic infrastructure (computer labs) and electricity in schools. Due to the preliminary requirements, there exists a list of barriers that resists the inclusion of ICT in developing countries like Pakistan [1]. Due to the lack of basic infrastructure, the schools of Chitral are not attractive for the teachers as well [2]. The majority of the teachers lack basic ICT skills and thus contribute to the digital divide. Moreover, the inclusion of ICT in the curriculum has never been given importance due to digital divide becoming severe in District Chitral.

According to Pakistan Education Statistics [3], 22.64 million children are out of school. Among these children, 49\% are girls and $40 \%$ are boys. Pakistan is having the secondhighest ratio of girls not enrolled in schools in the entire world [4]. This makes the scenario worse. This situation has given rise to the female education crisis in recent times as the tribal communities are reluctant to female education, and another factor is the militancy that has now been overcome. However, parents in Khyber Pukhtunkhwa (KP) province are reluctant to send their daughters to schools, and the same is the case in the Federal Administrative Tribal Area (FATA) and Balochistan province. The main reasons for keeping the girls out of the schools are cultural traditions, militancy in past recent decades, unsuitable schooling environments, and financial constraints of the parents.

According to the Annual Statistical Report Government Schools in Khyber Pakhtunkhwa for the year, there are only 11,697 schools for girls compared to 21,893 for boys in the province of KP [5]. This shows the indifference of the government policies to consider female education equally important in the country. The objective of this research is to integrate ICT and to address the ICT gap related to girl education in the District Chitral. Moreover, the Wi-FiBCDs were given to the female schools of Chitral for evaluation purposes.

1.2. Information and Communication Technology (ICT). Information and communication technologies (ICTs) have greatly affected human life nowadays. ICT (telephones, television, computers, and Internet) gives opening and easy access towards global shared knowledge around the world in almost all fields of life. Unfortunately, ICT is not accessible all over the world [6].

ICT technologies have an important role in making human life enhanced and modernized in this modern era. It is essential to avail all ICT applications to cope with the modern challenges in the current society. Similarly, ICT brings treasured and worthwhile information in the fields of technology, social, political, and economic philosophy in the world of academic pursuit. The sectors of education, academics, and research are also being affected positively due to substantial changes in the field of ICT [7].

1.3. Role of ICT in Education. The growing development in ICT remarkably revolutionized the world in the 21st century to enhance and modernize it in this modern era. ICT is the demand of the day to make progress in the world of academics, education, and research. Hence, it is indispensable to use ICT in academics to explore and teach the learners updated materials and skills with the latest techniques. Educationalists and policymakers try to restructure their whole academic setting to fill the technical gap in the process of learning and teaching. This restructuring process requires actual implementation of technology in the existing educational setting to provide students with subject-related knowledge and to enhance profession maturity in learners or scholars [8].

The initiation of ICT in academics ensures communication with each other via email, mailing lists, and meeting rooms. ICT provides faster and convenient access to extensive and current information; ICT can also be used to perform complex mathematical and statistical calculations. In addition, ICT is the best tool to publish research findings and conclusions [7].

According to [9], using ICT for teaching in learning improves students' performance, increases motivation, enhances confidence, and improves positive attitude [10], suggesting that ICT being well incorporated in teaching and learning produces a positive impact on learning outcomes and improves motivation and creates enthusiasm in learners.

According to [11], the outline of ICT on teaching in learning supports better assignment and deep learning. Using ICT makes the learner attitude positive and boosts confidence. ICT is a kind of soft power to enhance economic skills that can develop technical strategies of the learners to get the opportunities of employment in the future. The development of ICT culture in schools is necessary to develop the strategic skills of the students.

1.4. ICT for Girls (In Digital Pakistan Policy 2017). The federal cabinet finally approved the long-awaited IT Policy of Pakistan and has issued it in the name of "Digital Pakistan Policy 2017." ICT in education can be used to empower young girls. The following are the main findings of ICT Education for girls in Digital Pakistan Policy 2017.

(1) Encourage the use of ICT among girls for their empowerment and to overcome the digital divide

(2) The initiation of ICT programs in girls' schools that can educate them in software skills. This education would be fruitful to find white-collar jobs in the future. The establishment of women empowerment centers and IT laboratories in schools that can build their (young girls) IT skills (computing, coding, and communication) in collaboration with other private sectors 
(3) The provision of special incentives to boost up digital services and strengthen IT culture in the region

(4) Strengthening international collaboration in ICT accessibility so that women and girls may have active partaking in digital society

1.5. Digital Divide: A Concept. The society of human beings from the very beginning is divided into so many aspects such as gender, caste, color, race, and ethnicity. The rapid advancement of ICT in the 20th century divides the people of the world once again and is named the digital divide. Digital divide means an unequal opportunity for people to access knowledge shared on the Internet. Digital divide exists also among the countries and within the countries. The developed countries are comparatively less digitally divided as compared to developing countries [12].

The Organization for Economic Cooperation and Development defines the term digital divide as "the gap among individuals, businesses, households, and geographic areas at different socioeconomic levels with regard to both their opportunities to access ICT and their use of the Internet for a wide variety of activities." The digital division shows differences within and among the countries. The digital divisions in homes depend upon income, education, and some other factors such as the size and type of house, age, gender, ethnicity, and linguistic backgrounds [12].

Basic ICT skills and infrastructure are necessary for people to use ICT facilities. The availability of ICT infrastructure positively contributes to overcoming the digital divide. The problem with rural communities in third world countries is the lack of access to information. The lack of infrastructure basically contributes to the lack of access to information in rural areas. The Wi-Fi-BCD and tablet computer will overcome the lack of ICT facility. Various studies have highlighted the role of individual use in measuring the digital divide [13].

These studies have revealed a positive relation between the individual use of ICT facilities (access and effective utilization of high and low digital divide in a society).

1.6. Barriers in Accessing ICT Services. Van Dijk and Hacker [14] find four types of barriers to access including mental access, material access, skill access, and usage access. Mental access is due to lack of initial digital experience, interest, computer worries, and disinterest in new technology. Material access is due to the nonavailability of computer and network connection, such as hardware, software, applications, and networks. The major portion of the research in digital divide is the study of physical access to personal computers and the Internet [15]. Skill access rises because of the lack of digital skills due to inadequate user-friendliness and inadequate education or social support. One needs access skills to use and command digital media technology; some people call these as digital skills [15]. Usage access arises due to the lack of significant usage opportunities. Some researchers claim that this gap is the diversity of application usage between different people, education levels, age, and gender [14].
1.7. Bridging the Digital Divide in Chitral. Considering the mentioned condition of the area and being part of the jurisdiction of the university, our institute recently established a specific project named Bridging the Digital Divide via Wireless Local Area Network on Raspberry Pi3 (Wi-Fi-BCD) worth Rs. 2.5 million in order to balance the inequality of ICT facilities at the Government Girls Secondary and Higher Secondary Schools of the District Chitral.

As a first step of the project which is the development and installation of Wi-Fi-BCD in their schools, thousands of high school students and their teachers will be benefited from the project. They will also know about the advantages of being connected through the project. The teachers will prepare their lectures with the help of the updated material shared by the international education experts. Moreover, the practitioner's confidence, the positive impact on teaching and learning, and the quality of education provided at these schools will also be enhanced which is one of the major objectives of this research project.

1.8. Organization of the Paper. The rest of the paper is organized as follows. Section 1 has introduced the concepts related to the study thoroughly. In Section 2, we describe the development of Wi-Fi-BCD. Section 3 throws light on the conceptual model, while Section 4 describes the research methodology adopted for this specific study. Section 5 presents the results. Finally, Section 6 concludes the paper.

\section{Wi-Fi-Based Content Distributor (Wi-Fi- BCD)}

The Wi-Fi-BCD is a digital content distributor, based on the Raspberry Pi. The beauty of Wi-Fi-BCD is that the contents are accessible without having an Internet connection. Furthermore, the Wi-Fi-BCD is a solar-based innovation; the contents are accessible even without electricity and Internet connection. Even if the area has no Internet connection and electricity, the Wi-Fi-BCD is the solution to distribute the contents as an offline library. With the small size and solarbased properties of the Wi-Fi-BCD, one can deploy anywhere in the school and college to distribute the preloaded digital content. The contents can easily be accessed using a tablet, mobile, computer, and laptop.

2.1. Wi-Fi-BCD Development. The Wi-Fi-BCD is a portable server, which is plug-and-play as well as offline. It stores educational contents and other educational material and makes the contents available offline via a wireless connection. It acts as a library of digital contents, which can be available by just pressing a button. The digital contents can be accessed via a smartphone or PC by typing the IP address in order to connect to the Raspberry Pi server.

When you are connected to the server, you can easily access the world's best free educational websites offline including Wikipedia and Khan Academy. You can play and download the videos and audios, preview, and download books. 
2.2. Specifications of the Wi-Fi-BCD. The specifications of the $\mathrm{Wi}-\mathrm{Fi}-\mathrm{BCD}$ are the following:

(i) Raspberry Pi3, 64-bit 1.2 GHz quad-core SBC

(ii) 64 GB SD card

(iii) Wi-Fi Dongle

(iv) 5-ampere charge controller

(v) $12 \mathrm{~V}$ DC battery inside/20-watt $12 \mathrm{~V}$ solar panel

The Wi-Fi-BCD is preloaded with thousands of opensource video content including offline KA Lite; Khan Academy content for math, physics, biology, chemistry, and several other subjects; RACHEL with world-famous books; Wikipedia for Schools; digital world map; health care; advanced school curricula; and many textbooks.

2.3. Raspberry Pi. The Raspberry Pi is developed by the Raspberry Pi Foundation in the UK. It is a single-board computer made for the purpose of enhancing basic computer science teaching in schools, colleges, and universities. Several generations of $\mathrm{R}-\mathrm{Pi}$ are released. All versions contain a Broadcom system on a chip (SoC), CPU, and GPU. The speed of the $\mathrm{CPU}$ ranges from $700 \mathrm{MHz}$ to $1.2 \mathrm{GHz}$ for the $\mathrm{R}-\mathrm{Pi} 3$, and the memory capacity is from $256 \mathrm{MB}$ to $1 \mathrm{~GB}$. SD cards are used to store OS and other programs. It also has the capabilities of HDMI, composite video output, $3.5 \mathrm{~mm}$ phone jack for audio, GPIO pins, Ethernet port, Wi-Fi 802.11n, and Bluetooth. Figures 1 and 2 show the R-Pi without and with a protective case.

2.4. RACHEL Server on Wi-Fi-BCD. The RACHEL (Remote Area Community Hotspot for Education and Learning) server is a portable offline server that can store educational contents, websites, and other educational material and make the content available offline over any local wireless network. The RACHEL server can make deploying a digital content library very easy, an initiative to make available rich educational contents to places where no Internet connection is available (worldpossible, 2018) (Connecting offline learners to the world's knowledge: URL: https://worldpossible.org).

2.5. System Development Phases. The Wi-Fi-BCD is built on the Raspberry Pi3 (Model B), on a 64 GB micro SD card with preloaded RACHEL content. Wi-Fi-BCD does not need an electricity connection or battery backup. It is recommended for an area with unreliable power. Table 1 shows the development phases of Wi-Fi-BCD, and Figure 3 shows the pictorial view of the network.

\section{Conceptual Research Model}

Technology acceptance is "the assessment of usage or rejection of ICT service" [16]. Diverse models with explicit elements set have been developed by information technology (IT) and information system (IS) scientists. The technology acceptance model (TAM), Theory of Reasoned Action (TRA), unified theory of acceptance and use of technology (UTAUT), and Diffusion of Innovation Model (DOI) are

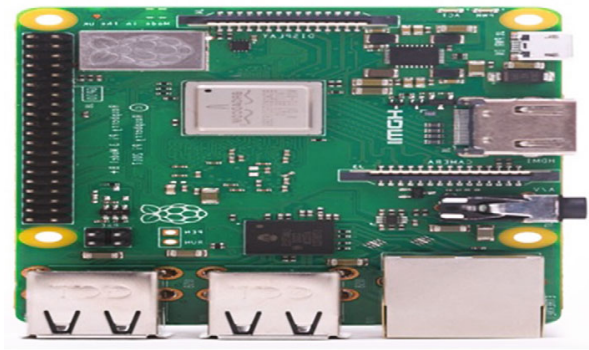

FIgURe 1: Raspberry Pi board.

the famous IT and IS acceptance models. These models are discussed as follows.

3.1. Theory of Reasoned Action (TRA). Theory of Reasoned Action (TRA) proposed by [17] is the most appropriate model regarding the study of user behavior; it is used in different research domains to predict user behavior. The TRA predicts the factors which affect human behavior to accept a particular system.

3.2. Unified Theory of Acceptance and Use of Technology (UTAUT). Unified Theory of Acceptance and Use of Technology (UTAUT) is generally used in the field of technology acceptance models. The unified theory of acceptance and use of technology explains user intentions to use a particular system and the usage behavior. The UTAUT model explains the influence of individual differences in the use of technology, thus adding control variables such as gender, age, and experience. The predictors of UTAUT are behavioral intention or usage, effort expectancy, performance expectancy, social influence, and facilitating conditions [18].

3.3. Technology Acceptance Model (TAM). The technology acceptance model (TAM) is the most cited and famous model to examine the user acceptance and use of IT and IS. The TAM model was developed by [19] from the TRA. The TAM model further explains why users will accept technology and what factors influence the acceptance of technology on users. This model has two cognitive factors perceived usefulness (PU) and perceived ease of use (PEOU). According to [19], PU means "the extent to which the person believes that using a particular system would enhance the performance of the individual." [19] defines PEOU as an individual's perception regarding the ease of use of a particular system. Simply, PU means the usefulness of a system, and PEOU means the easy use of the system.

3.4. Reasons to Choose TAM Model. The TAM model is used in studies based on IT systems to evaluate their effectiveness for the users. The TAM was proposed by [19] and is widely used to explore users' acceptance of IT and IS. The model is explicitly designed to know the acceptance of ComputerBased Technologies (CBT) in a workplace. This study, therefore, is constructed to include

(1) perceived usefulness (PU)

(2) perceived ease of use (PEOU) 


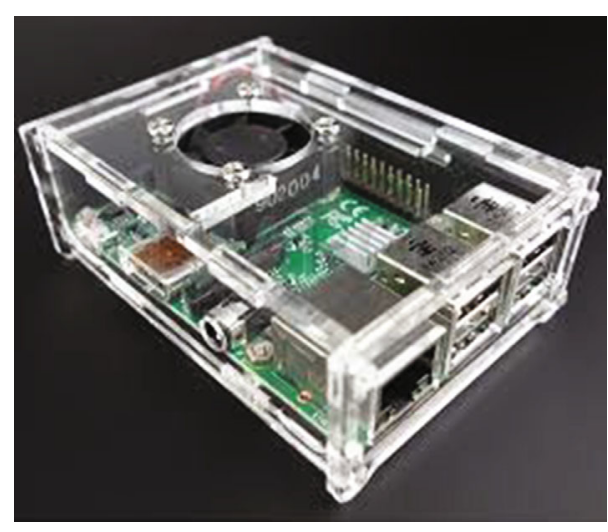

Figure 2: Raspberry Pi casing.

(3) attitude towards using (ATU)

(4) behavioral intention (BI) to use

The main objective of this study is to develop and evaluate a model of the influence of system characteristics related to the acceptance of computer-based ISs by users. The TAM model is developed with two major objectives: to improve our perception of user acceptance processes and to provide the theoretical basis for testing this framework of user acceptance which will enable the system developers to test their proposed systems before launching them for implementation. This prototype helps further improvement of the system.

In the TAM model as shown in Figure 4, the external variables are the design features of the IT or IS. The PEOU and PU are the cognitive responses of users, the ATU is an effective or accepted response, and the $\mathrm{BI}$ is the actual use of the system. The PEOU, PU, and ATU are the user motivation.

The TAM model consisting of six major elements which include external variable (EV), PEOU, PU, BI, ATU, and actual use (AU) and a set of relations among them is hardly used by scholars without modifications $[20,21]$. The researchers often modify the model to fulfill the requirements of particular subject and research questions. Also, the researchers need to modify the model by choosing and concentrating on a portion of the initially proposed components and relations, extending the model by including new components, and recommending new relations among the components $[22,23]$.

No doubt, the TAM model is famous and is a cited research model regarding the acceptance of technology [24]. The TAM model is widely tested in different scenarios and content and verified to be reliable and valid by explaining the acceptance of IS and IT $[25,19,18]$. In the light of the above discussion, a modified research model based on TAM is designed, which is discussed as follows.

3.5. Modified TAM Model for Our Research. Luhamya et al. [26] have discussed different models and theories about ICT in education. They discussed the TRA model developed by Ajzen and Fishbein (1980). In fact, the TRA model has Actual Behavior $(\mathrm{AB})$ as its main variable. Actual Behavior is an individual's response which can be observed in each situation with respect to a given target.

The related literature is showing six theories regarding ICT, such as the TAM, the TRA, the Theory of Planned Behavior (TPB), the Technology-Organization-Environment (TOE) framework, the Technological Pedagogical Content Knowledge (TPACK) framework, and the UTAUT [26]. All the stated above theories have focused on student's motivation, practitioner's confidence, and improvement in teaching and learning in one or another way. Our modified TAM model is shown in Figure 5.

In fact, the Wi-Fi-BCD is a kind of ICT in education that helps to improve students' outcome. The development, distribution, and installation of Wi-Fi-BCD in Girls Secondary and Higher Secondary Schools of Chitral will motivate students for higher outcomes, will develop confidence in using ICT, and will make effective and convenient the teaching and learning process.

3.5.1. Demographic and Topographic Factors. Access to ICT is also dependent on demographic or topographic factors; also, the geographical location plays an important role in accessing ICT. According to [14], the major measure of the research of the digital divide is dedicated to the observation of physical access to personal computers and the Internet based on demographic factors that include gender, age, income, and education. According to [27], the weightier cultural, social, and mental reasons behind the digital divide have not been addressed so far, and findings show that income is the most significant factor behind physical access followed by age and education, respectively.

3.5.2. Student Motivation (SM). Motivation has been one of the key concepts of pedagogical psychology for a long time. It is a process which involves objectives as well as physical and mental activities. On a general level, it encompasses various events that cause shifts and lead to appropriate measures. Järvelä [28] claimed that it was not prior to 1980 that motivation was transferred from laboratories to the natural learning environment and that until then studies on motivation had very little impact on the teaching process. Nowadays motivation is crucially related to the learning process and learning achievements. In fact, it is of great interest to the students in using Wi-Fi-BCDs for high achievements.

3.5.3. Positive Impact of Wi-Fi-BCD on Teaching and Learning (PI). Primarily, the content server was used to facilitate student learning. Teachers have increased their personal and professional uses of computers [29]. Alongside, these increases in teachers' professional uses are increased in the reported instructional uses of computers in the classroom.

3.5.4. Practitioner's Confidence in Using Live Technology $(P C)$. As with other professionals, it is expected that teachers use technology in ways that extend and increase their effectiveness. Here, practitioners' confidence means how boldly the teachers and students can use computers and tablets to browse data and to write, save, or delete data files. 
TABLE 1: Wi-Fi-BCD development phases.

\begin{tabular}{lc}
\hline Phase & Deliverable \\
\hline Phase 1 & Need a Raspberry Pi \\
Phase 2 & 64 GB SD card (to host the operating system and RACHEL Pi) \\
Phase 3 & An open-source RACHEL Pi image \\
Phase 4 & Download RACHEL Pi from FTP: ftp.worldpossible.org on FTP Client Filezilla \\
Phase 5 & The downloaded RACHEL Pi image will be written on SD card \\
Phase 6 & Insert the SD card into the Raspberry Pi and power it on \\
Phase 7 & Look for a network named RPI, connect it \\
Phase 8 & Enter 10.10.10.10 into browser address bar, the RACHEL content will be displayed
\end{tabular}

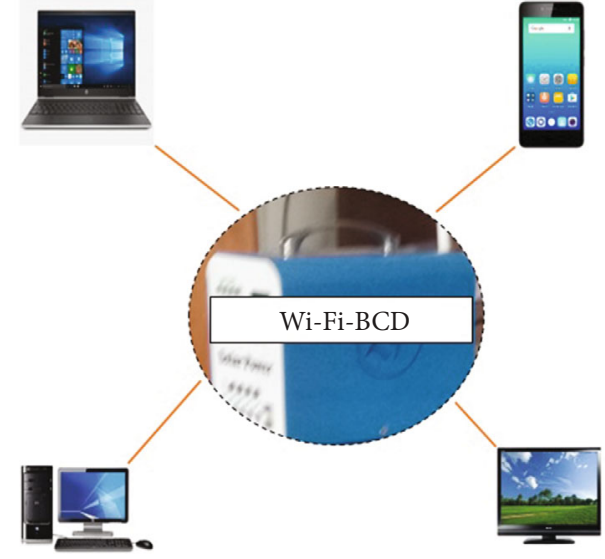

Figure 3: Pictorial view of network architecture.

3.5.5. $W i-F i-B C D$. This is thoroughly discussed in Section 2 .

3.5.6. Perceived Ease of Use (PEOU). Davis et. al [19] define $\mathrm{PEOU}$ as an individual's perception regarding the ease of use of a particular system, i.e., whether it is easy to understand or difficult to learn and use. It is a concept which refers to users' perception of how an IS is difficult to use. Moreover, it is the evaluation of the degree of using the technology with minimum effort.

3.5.7. Perceived Usefulness (PU). According to [19], PU means "the extent to which the person believes that using a particular system would enhance the performance of the individual." In this study, we must find the use of Wi-FiBCD beneficial, particularly in terms of bridging the digital divide more effectively. Furthermore, according to [30], the concept of perceived usefulness is the perception of a user of a given technology to achieve his work goals.

3.5.8. Attitudes towards Using (ATU). Davis et al. [19] define attitude as the positive or negative feelings of a user of a system. The ATU, in this study, is to assess the attitudes towards using the $\mathrm{Wi}-\mathrm{Fi}-\mathrm{BCD}$ for bridging the digital divide. Positive attitude certainly helps to overcome the digital divide and improve the contents of the $\mathrm{Wi}-\mathrm{Fi}-\mathrm{BCD}$. The more the use of the $\mathrm{Wi}-\mathrm{Fi}-\mathrm{BCD}$, the more the improvement.

3.5.9. Behavioral Intention (BI). The BI is the degree of the strength of one intent to do a specified task (behavior). The
$\mathrm{BI}$ is recognized as an exceptionally main construct in the TAM study as it is proposed to be a key measure in user acceptance study [31]. It was devised from the TRA by [17]. Earlier research has shown that BI has a direct relationship to the actual use of a given technology. The features of this design are important as they have the capability to influence the perception of the users; they directly touch the PU and PEOU. Without affecting the attitude or behavior, these features indirectly influence the perception of the users regarding its usefulness and comfort.

3.6. Relationship between Model Variables. The modified TAM model used in this study is aimed at examining the effect of Wi-Fi-BCD for bridging the digital divide in Girls School of Chitral. The required relationship between SM, PI, PC, PEOU, PU, ATU, and BI is examined to find the effects of Wi-Fi-BCD for bridging the digital divide. All the relationships between the above variables are tested; if found positively significant, the effects of the Wi-Fi-BCD will be positive on bridging the digital divide.

3.6.1. Relationship of Wi-Fi-BCD with SM, PI, and PC. In the modified TAM model for the study, the Wi-Fi-BCD (WCD) is a dependent variable for student motivation for higher outcomes (SM), practitioners' confidence (PC) in using livetechnology, and positive impact of $\mathrm{Wi}-\mathrm{Fi}-\mathrm{BCD}$ on teaching and learning (PI). A significant relationship of the Wi-FiBCD with SM, PI, and PC means that the Wi-Fi-BCD effect is positive to bridge the so-called digital divide.

3.6.2. Relationship of Wi-Fi-BCD with PEOU and PU. The $\mathrm{Wi}-\mathrm{Fi}-\mathrm{BCD}$ is a dependent variable for the PEOU and PU. A positive association of Wi-Fi-BCD with PEOU and $\mathrm{PU}$ means that the Wi-Fi-BCD effect is positive to bridge the digital divide. A positive relationship of PEOU and $\mathrm{PU}$ with Wi-Fi-BCD means that teachers and students found the Wi-Fi-BCD easy to use and found it useful.

3.6.3. Relationship between PEOU and PU. Davis et al. [19] accomplished several experimental studies to confirm the TAM model, based on the independent variable PEOU and PU with the dependent variable ATU. In the results of the experimental studies, Davis et al. found the correlation of PU positively significant with PEOU and ATU. Davis et al. also found the correlation of PEOU with ATU positively significant. But the correlation of PU with ATU was more 


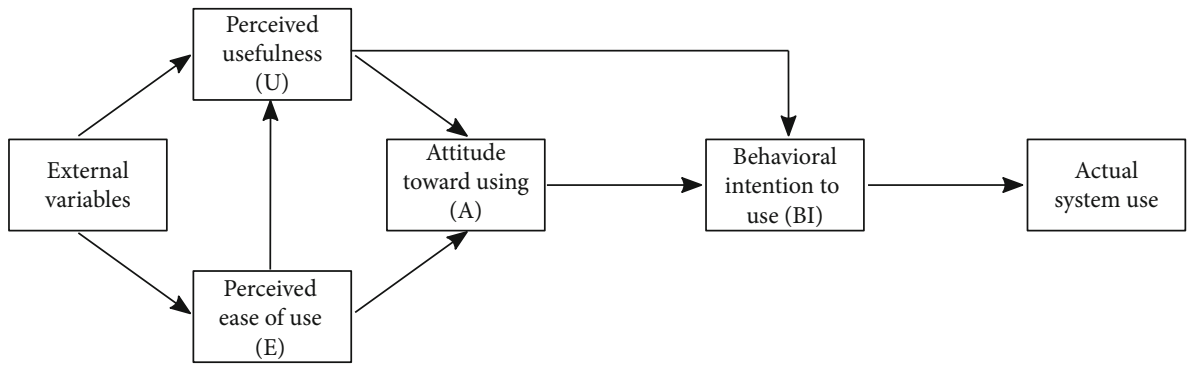

Figure 4: TAM model proposed by Davis (1986).

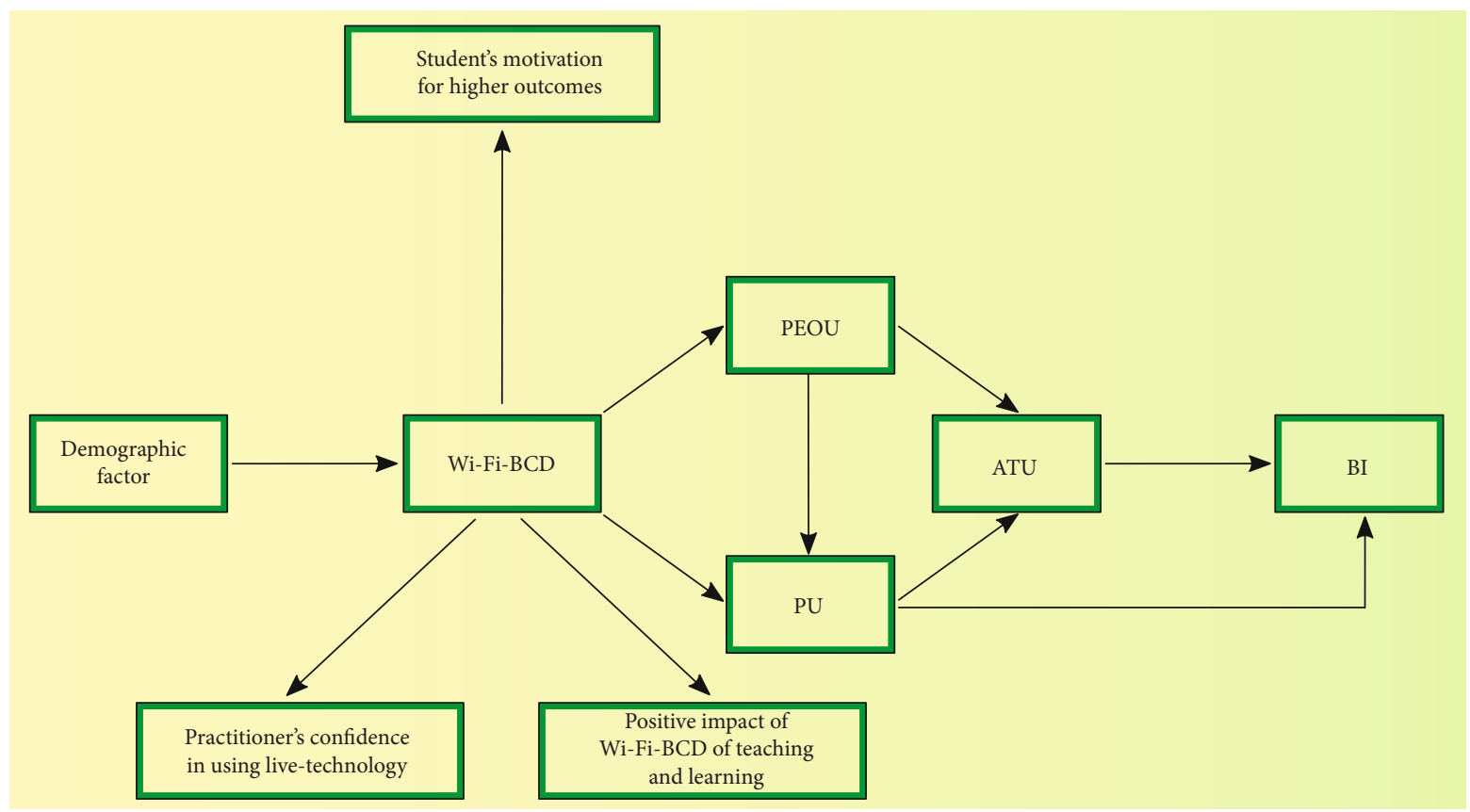

FIgure 5: Modified TAM model for our research.

strongly positively significant. According to [19], the PEOU is also a dependent variable for the PU; the high PEOU of a system increases the PU of that system [30, 19]. Based on [19] assumption, the perceived ease of use of the $\mathrm{Wi}-\mathrm{Fi}$ $\mathrm{BCD}$ will result in $\mathrm{PU}$ of the Wi-Fi-BCD to bridge the digital divide.

3.6.4. Relationship between PU and ATU. According to [32], the PU of IT and IS is the most important factor for ATU. According to [33], PU has a significantly strong association with ATU than PEOU. According to [19], the PU has a strong effect on ATU and is verified in several previous and current studies; the ATU is the most important factor to determine the actual usage of a system. For the Wi-Fi-BCD, the higher the effect of PU on ATU, the higher will be the usage of the Wi-Fi-BCD.

3.6.5. Relationship between PEOU and ATU. Vallerand et al. [17] proposed that the ATU of the system is determined from the ease of use of that system. PEOU is an independent variable for ATU and a dependent variable for PU. According to the assumption of [19], PEOU and PU will predict attitude towards using the Wi-Fi-BCD.

3.6.6. Relationship between ATU and BI. According to Leonard et al. [34], the ATU has a direct effect on behavioral intention to use. BI is a dependent variable for ATU and $\mathrm{PU}$; from the discussion above, the behavioral intention to use is mainly dependent on ATU and PU. The attitude towards using and $\mathrm{PU}$ will predict the $\mathrm{BI}$ of the $\mathrm{Wi}-\mathrm{Fi}-\mathrm{BCD}$ (actual usage of Wi-Fi-BCD) for bridging the digital divide.

3.7. Aims of the Adopted TAM Model. The study is to find the effects of Wi-Fi-BCD to bridge the digital divide. The relationship between the variables Wi-Fi-BCD, SM, PI, PC, PEOU, PU, ATU, and BI is analyzed for the purpose, to know the effects of Wi-Fi-BCD for bridging the digital divide. As per the modified TAM model, the following path relationship is tested to know the effects of Wi-Fi-BCD for model fitness on the data collected.

(1) The relationship of Wi-Fi-BCD with SM, PI, and PC

(2) The relationship of Wi-Fi-BCD with PEOU and PU 
(3) The relationship of PEOU and PU

(4) The relationship of PEOU and PU with ATU

(5) The relationship of ATU and BI

\section{Research Methodology}

This section describes the methodology, which has been followed to accomplish the objectives and answer the research questions of this study. Saunders and Lewis [35] define the research methodology as the collection of data, interpretation of data, and conclusion of information with a distinct objective. Methodology plans the techniques for collection of data and answering research questions [36]. This section describes the strategies for the research design and the research method used in this study.

4.1. Research Design. The research design is the process of conducting the research. It shows the plan of how the research is carried out. The objective of a research design is to propose the plan to make the experimental analysis that is used to answer the research question and provides sound results. A quantitative research approach is used in this study, which was initially developed in natural science to study science phenomena [37]. Today, quantitative research is well accepted in the education and social sciences. This method makes use of numerical analysis. The problem is determined from existing literature. The data collected from the target population through the survey tool is analyzed by statistical techniques such as descriptive statistics (percent distribution), Pearson correlation, standard multiple regression, and exploratory factor analysis.

4.2. Reasons for Choosing the Quantitative Research Method. The quantitative research method is selected on the ground that it depends on measurements of various scales to produce numbers that can be analyzed, using statistical methods, i.e., descriptive, and inferential statistics. The quantitative method is objective, unbiased, and value-free [37].

4.3. Research Strategy. The research strategy used for this research is a case study. According to [38], a case study is a research strategy not a specific method. According to [39], a case study explores properties, attitudes, effects, and actions of individual or group characteristics with the help of a questionnaire, observation, interviews, and document analysis. A case study is used for in-depth understanding of a certain phenomenon or problem.

4.4. Research Site. This research is carried out at Government Girls Secondary and Higher Secondary Schools of District Chitral, Khyber Pukhtunkhwa, Pakistan. The data is collected from the schools where the Wi-Fi-BCDs are fully functionally equipped. The Deputy Commissioner Chitral and District Education Officer (female) gave written permission to the researcher to collect the data from these schools. The data was collected from the headmistress, teachers, and students.
TABLe 2: Population and sample.

\begin{tabular}{lcc}
\hline Respondent & Population $(N)$ & Sample size $(n)$ \\
\hline Headmistress & 25 & 20 \\
Teacher & 232 & 89 \\
Student & 3317 & 432 \\
\hline
\end{tabular}

4.5. Population and Sample. According to [37], a population is a big group of individuals that obey explicit criteria, for which the scholar planned to simplify the results of the study. The number of schools and teachers is taken from the Annual Statistical Report Government School [4]. There are a total of 232 female teachers and 3317 students enrolled in 25 Girls Secondary and Higher Secondary Schools of Chitral. The data is shown in Table 2.

According to [40], at least $10 \%$ of the population has a reasonable representation for a large population. In the case of a small population, then $20 \%$ representation may be required. To determine the sample size, $40 \%$ is used for teachers. The number of students is large; for student sample size, [41] suggests that a $15 \%$ sample size is acceptable. A stratified random sampling technique is used because stratified random sampling is the best sampling technique as it produces a minimum sample error [42].

4.6. Data Collection Instrument. For collection of data, a close-ended questionnaire was developed. It comprises two parts: part A: demographic data (for teacher only) and part B: Wi-Fi-BCD from items 1 to 4 (4 items), SM from items 5 to 8 (4 items), practitioner confidence in using live technology (PCLT) from items 9 to 11 (3 items), and positive impact of content server on teaching (PICST) from items 12 to 14 ( 3 items), similarly, PEOU from 15 to 18 (4 items), PU from 19 to 22 ( 4 items), the ATU from 23 to 24 ( 2 items), and the BI from 25 to 26 ( 2 items). These (26) items were perceived through a Likert scale ranging from 1 to 5 options (" 1 : strongly disagree, 2: disagree, 3: undecided, 4: agree, and 5: strongly agree").

4.7. Reliability. Reliability is the measure of the degree to which a tool produces repeatable results subsequently for several trials [43]. To measure the reliability of the data gathered for research, the investigator uses a test-retest procedure in which the tool is checked over and again for related subjects. For reliability, this study examined the value of the following tests. For internal reliability, the value of Cronbach alpha $\geq 0.7044$.

4.8. Validity. Validity is concerned that the findings and results are likely the same as expected. Validity is defined as a method measuring accurately what we suppose to measure. Validity is the accuracy and meaningfulness of research results [35]. Validity refers to the ability of an instrument that should be measured for a structure. According to [44], four tests that face effectiveness, convergence, build, and distinguish effectiveness are important to ensure the effectiveness of any structure. 
4.9. Normality of the Data. The degree to which the distribution of sample data corresponds to a normal distribution [44], while normal distribution refers to such a distribution in which the horizontal axis shows the distribution of possible values of a variable. Apart from this, normality was also checked through KMO value and Bartlett test of sphericity.

4.10. Data Collection Procedure. For data collection, a quantitative approach will be used aimed at the generalization of research findings. In this research study, the constructs named as (1) demography, (2) Wi-Fi-BCD, (3) student motivation for higher outcomes, (4) practitioner confidence in using live technology, (5) positive impact of the content server on teaching and learning, (6) PEOU, (7) PU, (8) ATU, and (9) BI are conceptualized. A closed-ended questionnaire is used having statements with choices from 1 to 5 ("1: strongly disagree, 2: disagree, 3: undecided, 4: agree, and 5: strongly agree"). The data is used to collect data from the students, teachers, and headmistress of Girls Secondary and Higher Secondary Schools of District Chitral. The questionnaires were distributed and collected by the researcher to assure a best response rate.

4.11. Data Analysis. The data collected from both teachers and students is analyzed using the Statistical Package for the Social Sciences (SPSS) software. Data analysis is the procedure for providing the structure, order, and interpretation to collected data [45]. The data analysis will be carried out with descriptive and inferential statistics. Descriptive statistics is used to represent the data in the form of frequencies, percentages, mean, and standard deviations. The descriptive statistic represents the data in tabular and graphical method, shrinking a huge amount of information into smaller and sample representation for easy interpretation [37]. Descriptive statistics is used to analyze the demographic factor of teachers (age and experience). The inferential statistics include the regression, correlation, and the exploratory factor analysis. For research question 1, correlation, regression, and exploratory factor analysis are used to answer. For research question 2, descriptive statistics (frequencies, percentage, mean, and standard deviations) and regression analysis are used to answer. Similarly, for research question 3, the Pearson correlation is used to answer.

4.12. Research Questions. The following are the research questions.

(1) The relationship between variables of the modified TAM model (Wi-Fi-BCD, SM, PI, PC, PEOU, PU, ATU, and BI are the variables of the modified TAM model) is tested for the model fitness on the collected data.

To find the model fitness on the data collected, path analysis through Pearson correlation, regression analysis for model fit, and exploratory factor analysis (EFA) are used.
(2) Does the Wi-Fi-BCD improve students' motivation for high-quality lesson outcome?

To find the effect of Wi-Fi-BCD on student motivation, descriptive statistics (frequencies, percentages, mean, and standard deviation) and regression analysis are used.

(3) Is there any significant correlation between Wi-FiBCD, SM, PI, PEOU, PU, PEOU, ATU, and BI ( $\mathrm{SM}=$ student motivation, $\mathrm{PI}=$ positive impact, $\mathrm{PC}=$ practitioner confidence, $\mathrm{PEOU}=$ perceived ease of use, $\mathrm{PU}=$ perceived usefulness, ATU = attitude towards using, and $\mathrm{BI}=$ behavioral intention) contributing to bridge the digital divide?

To find a significant relationship among $\mathrm{Wi}-\mathrm{Fi}-\mathrm{BCD}, \mathrm{SM}$, PC, PI, PU, PEOU, ATU, and BI, Pearson correlation analysis is used.

\section{Results and Discussion}

This section presents analysis, presentation, and interpretation of results and findings. The data is analyzed about the variables such as demographics, student motivation for higher outcomes, practitioner confidence in using live technology, positive impact of Wi-Fi-BCD on teaching and learning, Wi-Fi-BCD, PEOU, PU, ATU, and BI. Summaries are presented from the information, obtained from the questionnaires collected from students, teachers, and headmistress. Descriptive statistics, regression, and correlation are used to evaluate the relationship between these factors and to check the model appropriateness for the study. Results are obtained from the data on the following statistical methods.

5.1. Reliability. Reliability is the measure of the degree to which a tool produces repeatable results subsequently for several trials [43]. To measure the reliability of the data gathered for research, the investigator used a test-retest procedure in which the tool is checked over and over again for related subjects. Data collected initially was a pilot test of the tools to confirm that they produce the required data or results. The tools were ensured to be reliable after they produced a reliability coefficient greater than 0.7 for its entire constructs. According to [44], Cronbach alpha greater than 0.7 is observed as sufficient and having good reliability. Cronbach alpha is used in the study to measure reliability, which is commonly used to measure internal consistency. The main objective of reliability is to make sure of the internal consistency of the instrument and its construct [46]. The measured values of different indices for reliability are given in Table 3, which shows that all the constructs are Cronbach alpha greater than 0.7 .

5.2. Validity. Validity means the ability of an instrument that should be measured for a structure. Validity refers to the degree of correctness, significance, and meaningfulness of inference based on research results [43]. Validation of the data is completed via content validity. According to [44], four tests that face effectiveness, convergence, build, 
TABLE 3: Reliability of the construct.

\begin{tabular}{lcc}
\hline Construct name & Symbol & $\begin{array}{c}\text { Cronbach } \\
\text { alpha }\end{array}$ \\
\hline Wi-Fi-Based Content Distributor & Wi-Fi-BCD & 0.786 \\
Student motivation & SM & 0.804 \\
Practitioner confidence on live & PC & 0.749 \\
technology & PI & 0.884 \\
Positive impact of Wi-Fi-BCD & PEOU & 0.806 \\
Perceived ease of use & PU & 0.801 \\
Perceived usefulness & ATU & 0.807 \\
Attitude towards using & BI & 0.783 \\
Behavioral intention & &
\end{tabular}

and distinguish effectiveness are important to ensure the effectiveness of any structure.

5.2.1. Content Validity. According to [47], content validity measuring of instruments is essential. Content validity helps to ensure construct validity, which provides confidence to the researchers about the tool. Content validity shows the degree that the tool covers the content that it is developed to measure. According to Lynn [48], researchers calculated two types of CVIs: the content validity of individual items (ICVI) and the content validity of the overall scale (S-CVI). The content validity index (CVI) is the percentage of respondents that rated the item as 4 or 5 (in the rating scale from 1 to 5 where 5 represents the highest agreement) [48]. The formula for calculating the I-CVI and S-CVI is given below:

$$
\mathrm{CVI}=\frac{\text { Number of judge rate options } 4 \text { or } 5}{\text { Total number of judges }} * 100
$$

According to [49], the acceptable CVI values should be 1 for a few expert three or four judges, 0.80 for 5 experts, and 0.78 for more than 5 or larger expert groups. The acceptable CVI for this study is determined to be 0.78 . The I-CVI value for the study ranges from 0.08 to 0.09 , and the S-CVI value for the study ranges from 0.798 to 0.92 .

5.2.2. Discriminant Validity. According to [50], if discriminant validity is not performed and factor analysis is misinterpreted, then results and measurement scales used in research may not function properly, and the assumptions made about relationships between variables under research may be incorrect. For example, if a relationship is confirmed between variables and in real it is no relationship, or the strength or weakness of the relationship is miscalculated (Type II error). The Pearson correlation matrix is used to determine the discriminant validity, which measures the linear dependence between two variables [36], suggesting a score between +1 and -1 . Table 4 shows that all values are in the range of +1 and -1 ; hence, the study meets the validity requirement [36].

5.3. Normality. A normality test is used to check that the data set is having a normal distribution. The skewness and kurtosis are checked to find the distribution of the data set. The normality test can also be performed with the peak (kurtosis) and the skewness of a distribution through a graphical representation [51]. The results are obtained with descriptive statistics of the factors to indicate that all the factors are skewed (either positive or negative), and the same has for kurtosis (either positive or negative). A test of normality is important as a normal distribution is usually essential for most inferential analyses [51].

Table 5 shows the estimations of skewness and kurtosis (for normal data, the $z$ value should be in the range of -1.96 to +1.96$)$. In view of Table 5 , the skewness and kurtosis are in normal span for the variable in this study (Wi-Fi-BCD, SM, PC, PU, PEOU, ATU, and Wi-Fi-BCD) are regularly appropriated. KMO value $=0.846(p \leq 0.01)$. The value of KMO indicates that the sample for the study is adequate [52]. Next, the ordinarily utilized Kaiser-Meyer-Olkin (KMO) measure of examining ampleness and Bartlett's test of sphericity was raced to see whether the specimen estimate is fitting for factor investigation and the quality of the relationship among the factors is critical [53].

5.4. Demographic Information of the Respondents. For indepth understanding of the questionnaire responses and the data examination, it is worth investigating the respondent's demographic information. The demographic information of respondent (teachers) age and teaching experience is shown in Tables 6 and 7.

Table 6 shows the demographic data of the 89 female teachers. Their ages range from 25 to 45 years. Out of these respondents, $5 \%$ were of the age of 25 , followed by $28 \%$ teachers whose ages were in the range of 26-30 years. Similarly, the teachers aging between 31 and 35 years were $47 \%$. Furthermore, teachers who were in the age range of 36-40 were $15 \%$. Lastly, teachers having age of more than 40 were $5 \%$. This can be seen in Figure 6 . Table 7 shows that only $1 \%$ of the teachers have an experience less than 1 year; $23.6 \%$ of the teachers have an experience from 1 to 5 years. Similarly, $31.5 \%$ of the teachers have an experience in the range of $6-10$ years, where $31.5 \%$ of the teachers have experience from 11 to 15 years. Furthermore, $10.1 \%$ of the teachers were in the range of an experience from 16 to 20 years. Lastly, $2.2 \%$ of the teachers have an experience of 21 years and above. Figure 7 represents the experience of the teachers.

5.5. Research Questions. To extract the information from the data collected and to find the effect of Wi-Fi-BCD for bridging the digital divide in Government Girls Secondary and Higher Secondary Schools of Chitral, the result of the research questions of this study will be analyzed and presented.

5.5.1. Research Question \#1. Does the relationship between variables (Wi-Fi-BCD, SM, PC, PI, PEOU, PU, ATU, and $\mathrm{BI})$ of the model fit and significant on the data collected?

(1) Path Analysis for the Model Fitness. As per the modified TAM model, the following path relationship is tested to know the effects of Wi-Fi-BCD for model fitness on the data collected. 
TABle 4: Pearson correlation matrix.

\begin{tabular}{|c|c|c|c|c|c|c|c|c|}
\hline & Wi-Fi-BCD & SM & $\mathrm{PC}$ & PI & PEOU & $\mathrm{PU}$ & ATU & $\mathrm{BI}$ \\
\hline Wi-Fi-BCD & 1 & & & & & & & \\
\hline SM & $0.794^{*}$ & 1 & & & & & & \\
\hline PC & $0.821^{*}$ & $0.430^{*}$ & 1 & & & & & \\
\hline PI & $0.807^{*}$ & $0.967^{*}$ & $0.826^{*}$ & 1 & & & & \\
\hline PEOU & $0.590^{*}$ & $0.470^{*}$ & $0.309^{*}$ & $0.333^{*}$ & 1 & & & \\
\hline $\mathrm{PU}$ & $0.794^{*}$ & $1.000^{*}$ & $0.430^{*}$ & $0.967^{*}$ & $0.470^{*}$ & 1 & & \\
\hline ATU & $0.487^{*}$ & $0.424^{*}$ & $0.300^{*}$ & 0.4004 & $0.541^{*}$ & $0.424^{*}$ & 1 & \\
\hline $\mathrm{BI}$ & $0.644^{*}$ & $0.772^{*}$ & $0.453^{*}$ & $0.726^{*}$ & $0.458^{*}$ & $0.772^{*}$ & $0.443^{*}$ & 1 \\
\hline
\end{tabular}

TABle 5: Normality of the data.

\begin{tabular}{lcccccccc}
\hline Variable & Wi-Fi-BCD & SM & PC & PI & PEOU & PU & ATU & BI \\
\hline Mean & 3.64 & 3.73 & 3.77 & 3.77 & 3.87 & 3.73 & 3.64 & 3.97 \\
Std. deviation & 0.926 & 1.09 & 0.927 & 1.13 & 1.10 & 1.09 & 1.04 & 1.07 \\
Variance & 0.859 & 1.19 & 0.861 & 1.29 & 1.22 & 1.19 & 1.09 & 1.14 \\
Skewness & -1.093 & -1.28 & -1.006 & -1.30 & -1.50 & -1.28 & -1.14 & -1.14 \\
Kurtosis & 0.689 & 0.385 & 0.545 & 0.372 & 0.899 & 0.385 & 0.705 & 1.24 \\
\hline
\end{tabular}

TABLE 6: According to age.

\begin{tabular}{lcc}
\hline Gender & Freq & $\%$ age \\
\hline Female & 89 & 100 \\
25 years & 5 & 5 \\
26-30 years & 25 & 28 \\
$31-35$ years & 42 & 47 \\
$36-40$ years & 13 & 15 \\
$41-45$ years & 4 & 5 \\
\hline
\end{tabular}

TABle 7: According to experience.

\begin{tabular}{lcc}
\hline Gender & Freq & \% age \\
\hline Less than year & 01 & 1.1 \\
1-5 years & 21 & 23.6 \\
6-10 years & 28 & 31.5 \\
11-15 years & 28 & 1.5 \\
16-20 years & 09 & 10.1 \\
21 years above & 02 & 2.2 \\
\hline
\end{tabular}

(1) Relationship of Wi-Fi-BCD with SM, PI, and PC

(2) Relationship of Wi-Fi-BCD with PEOU and PU

(3) Relationship of PEOU and PU

(4) Relationship of PEOU and PU with ATU

(5) Relationship of ATU and BI

The above path relationships are tested to know the effects of Wi-Fi-BCD for model fitness on collected data.
To find out the relationship, Pearson's correlation test is used, to examine the (positive or negative, strong, or weak) association between the variables. Table 8 displays the Pearson correlation matrix.

(2) Relationship of Wi-Fi-BCD with SM, PI, and PC. Table 8 presents that $\mathrm{Wi}-\mathrm{Fi}-\mathrm{BCD}$ has a highly significant positive correlation between SM, PI, and PC, Wi-Fi-BCD with SM $(r=0.794, p \leq 0.01)$, Wi-Fi-BCD with PI $(r=0.807, p \leq$ $0.01)$, and Wi-Fi-BCD with PC $(r=0.821, p \leq 0.01)$.

(3) Relationship of Wi-Fi-BCD with PEOU and PU. Table 8 presents that Wi-Fi-BCD has a highly significant positive correlation between PEOU and PU, Wi-Fi-BCD with PEOU $(r=0.590, p \leq 0.01)$, and Wi-Fi-BCD with PU $(r=0.794$, $p \leq 0.01)$.

(4) Relationship of PEOU and PU. Table 8 shows PEOU and PU relationship with $r=0.470, p \leq 0.01$; the PEOU and PU have significant positive relationships.

(5) Relationship of PEOU and PU with ATU. Table 8 shows PEOU and ATU relationship with $r=0.541, p \leq 0.01$; the relationship of PU and ATU is $r=0.424, p \leq 0.01$. The relationship of PEOU and PU with ATU is significantly positive.

(6) Relationship of ATU and BI. Table 8 shows ATU and BI relationship with $r=0.443, p \leq 0.01$; the relationship of ATU with BI is significantly positive. All of the above relationships are highly positively significant with each other, which shows that the stated path relationships mentioned in the previous section are supported by the data collected. The model fitness for the data collected is also tested with regression analysis for $R^{2}$ and $F$ value. 


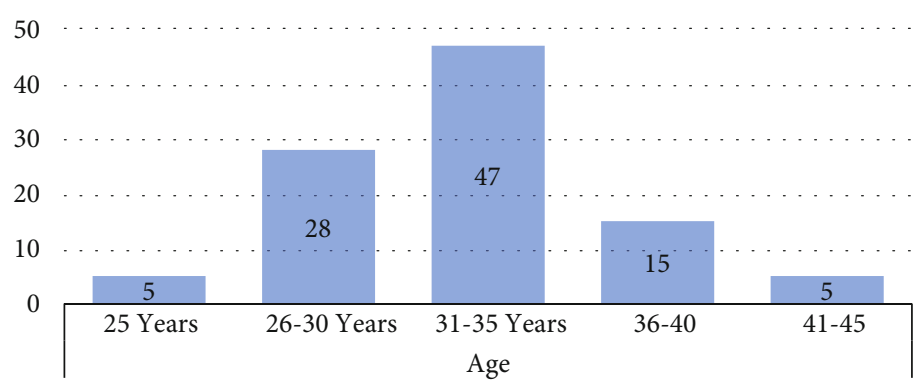

FIGURE 6: Classification according to age.

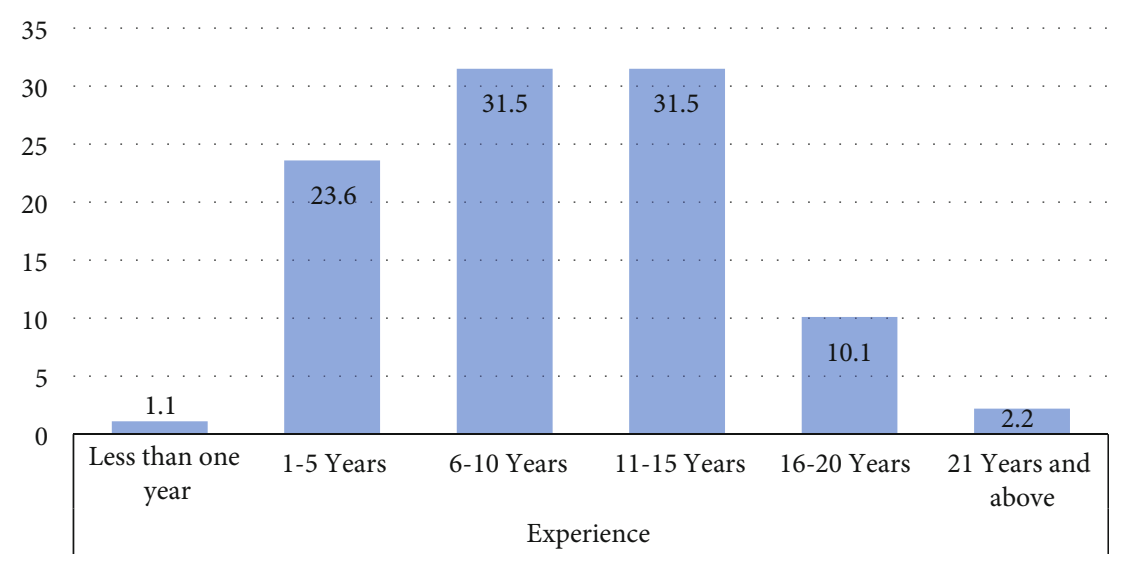

FIgURE 7: Classification according to experience.

TABle 8: Pearson correlation matrix.

\begin{tabular}{|c|c|c|c|c|c|c|c|c|}
\hline & Wi-Fi-BCD & SM & PC & PI & PEOU & PU & ATU & $\mathrm{BI}$ \\
\hline Wi-Fi-BCD & 1 & & & & & & & \\
\hline SM & $0.794^{*}$ & 1 & & & & & & \\
\hline PC & $0.821^{*}$ & $0.430^{*}$ & 1 & & & & & \\
\hline PI & $0.807^{*}$ & $0.967^{*}$ & $0.826^{*}$ & 1 & & & & \\
\hline PEOU & $0.590^{*}$ & $0.470^{*}$ & $0.309^{*}$ & $0.333^{*}$ & 1 & & & \\
\hline PU & $0.794^{*}$ & $1.000^{*}$ & $0.430^{*}$ & $0.967^{*}$ & $0.470^{*}$ & 1 & & \\
\hline ATU & $0.487^{*}$ & $0.424^{*}$ & $0.300^{*}$ & $0.400^{*}$ & $0.541^{*}$ & $0.424^{*}$ & 1 & \\
\hline BI & $0.644^{*}$ & $0.772^{*}$ & $0.453^{*}$ & $0.726^{*}$ & $0.458^{*}$ & $0.772^{*}$ & $0.443^{*}$ & 1 \\
\hline
\end{tabular}

5.5.2. Regression Analysis for Model Fitness. Model fitness can be checked through model summary obtained through regression analysis. Similarly, $p$ value in ANOVA can also confirm model fitness. The variable $\mathrm{Wi}-\mathrm{Fi}-\mathrm{BCD}$ is entered as a dependent variable, whereas PEOU, PU, ATU, and BI are entered as independent variables (predictors). From Table 9, it is found that Wi-Fi-BCD is entered as a dependent variable, whereas PU, PEOU, ATU, and BI are entered as independent variables. Results of the model summary show that the value of $R^{2}(0.777)$ shows that the proposed model is $77 \%$ found to fit with the collected data. Similarly, Table 10 shows the $p$ value (0.01) in ANOVA results, which also confirms model fitness on the collected data.
5.5.3. Exploratory Factor Analysis (EFA). Sample size is important for EFA analysis; according to Field (2005), a sample size of 300 is fit for EFA analysis, while other researchers proposed 10 samples for each item [54], proposed for each item of 5 cases. The sample size for our study is 521 , which is fit to perform EFA. The KMO value must be greater than 0.5 ; if the KMO value is less than 0.5 , it means that the sample is not fit to perform the EFA.

Exploratory factor analysis is used to find meaningful patterns in large data sets; EFA has the advantage as it determines which of the items hang together in the form of sets. The EFA method is used to highlight many relationships among different items in a more simple and parsimonious way. 
TABLE 9: Model summary.

\begin{tabular}{lcccc}
\hline Model & $R$ & $\begin{array}{c}R \\
\text { square }\end{array}$ & $\begin{array}{c}\text { Adjusted } R \\
\text { square }\end{array}$ & $\begin{array}{c}\text { Std. error of the } \\
\text { estimate }\end{array}$ \\
\hline 1 & $0.882 \mathrm{a}$ & 0.777 & 0.767 & 0.44773 \\
\hline
\end{tabular}

TABLe 10: Table of ANOVA.

\begin{tabular}{lcccccc}
\hline Model & $\begin{array}{c}\text { Sum of } \\
\text { squares }\end{array}$ & Df & $\begin{array}{c}\text { Mean } \\
\text { square }\end{array}$ & $F$ & Sig. & \\
\hline \multirow{4}{*}{1} & Regression & 58.772 & 4 & 14.693 & 73.295 & $0.000 \mathrm{~b}$ \\
& Residual & 16.839 & 84 & 0.200 & & \\
& Total & 75.611 & 88 & & & \\
\hline
\end{tabular}

5.5.4. Scree Plot. The scree plot in Figure 8 shows the variation of the curve. The scree plot shows the variance explained by each item in the EFA analysis. The $y$-axis is the eigenvalue, and the $x$-axis is the factors.

5.5.5. KMO and Bartlett's Test. The Kaiser-Meyer-Olkin measure of sampling adequacy value should be greater than 0.70 . The significant value in the last row should be significant (less than 0.05), indicating that the correlation matrix is significantly different from an identity matrix, in which correlations between variables are all zero. The KMO and Bartlett test of sphericity are used to explain that correlations between items were appropriately high for EFA. Table 11 shows KMO and Bartlett test.

The purpose of EFA analysis is to determine empirically whether the participants in our survey responded similarly to questions based on PEOU, PU, ATU, and BI. For this purpose, we run factor analysis using the principal axis factoring method and specify the number of factors to be four (because our conceptualization of the underlying phenomena is based on a scale of four variables, i.e., PEOU, PU, ATU, and BI. Table 12 shows the EFA correlation matrix.

A positive correlation between two variables means that both are in the same direction, while the negative correlation means that if the value of one variable increases, the other value decreases.

5.5.6. Communalities. The basic purpose of communalities is to represent the relation between all the questions (i.e., the squared multiple correlations between the item and all other items). Table 13 shows the communalities of EFA; communalities are said to be $R^{2}$ for each of the variables included in the EFA analysis. Table 13 shows the percentage of variance of each item that is explained by the elements.

5.5.7. Rotated Factor Matrix. This is one of the important matrices in EFA analysis. Actually, this is where we see a number of factors underlying a construct. First, we observe the table and count physically how many clusters there are. So, if there are three clusters, it means that there are three variables. If there are four clusters, it means that there are four variables. Ideally, we should first count the clusters, then analyze each question within the cluster, and based on thematic analysis, we infer information about the variable. In simple words, we read all the questions within each cluster again and again to see what common area they are focusing on. In our study, there are four clusters which mean that the items are loading exactly the way they were expecting. Table 14 shows that all factor loading is greater than 0.6 except the PEOU1 and PEOU4, according to [55], for a good fitness sample size not matter, but the factor loading shall be greater than 0.6. The KMO value is $0.860(p \leq 0.01)$, and the Cronbach alpha of all the constructs is greater than 0.07 . According to Table 14, the model is a reliable one to fit the collected data. Table 15 shows the descriptive statistics of EFA Analysis.

5.6. Research Question \#2. Does the Wi-Fi-BCD effect improve students' motivation for high-quality lesson outcomes?

5.6.1. Descriptive Analysis of the Question. To organize, summarize, and reduce, a large set of information descriptive statistics is used, which transforms a set of observations into numbers [37]. Graphical representation of information and calculation of range, minimum, maximum, mean, mode, median, standard deviation, and variance are based on descriptive statistics. The graphical representation technique is used to reduce a large scale of information into smaller representation for easy interpretation [37].

Based on the exploratory nature of the research question, descriptive statistics is used to analyze the data. While presenting the descriptive reports, only high percentages have reported against each statement. Six statements with five response options are asked from the respondent with the objective to know if the Wi-Fi-BCD improves students' motivation.

Table 16 presents the concise results in which the respondent is either strongly disagree, disagree, undecided, agree, or strongly agree to the research question that the Wi-Fi-BCD improves student motivation. The respondents strongly agree, and agree responses against each question are as follows.

(i) Learning becomes fun (75\%)

(ii) Enhances students' interest (71\%)

(iii) Motivates to learn new things (73\%)

(iv) Most of the students take interest in using (72\%)

Table 17 shows that the mean value of all the questions is greater than 3, which reflects that the response of the majority respondents is either strongly agree or agree that the $\mathrm{Wi}$ Fi-Based Content Distributor improves student motivation.

5.6.2. Inferential Analysis of the Question. According to [50], regression analysis is an appropriate method for TAM models to measure the relationship between model variables. According to [20], a linear regression model is frequently used in TAM model analysis. Linear regression is based to 


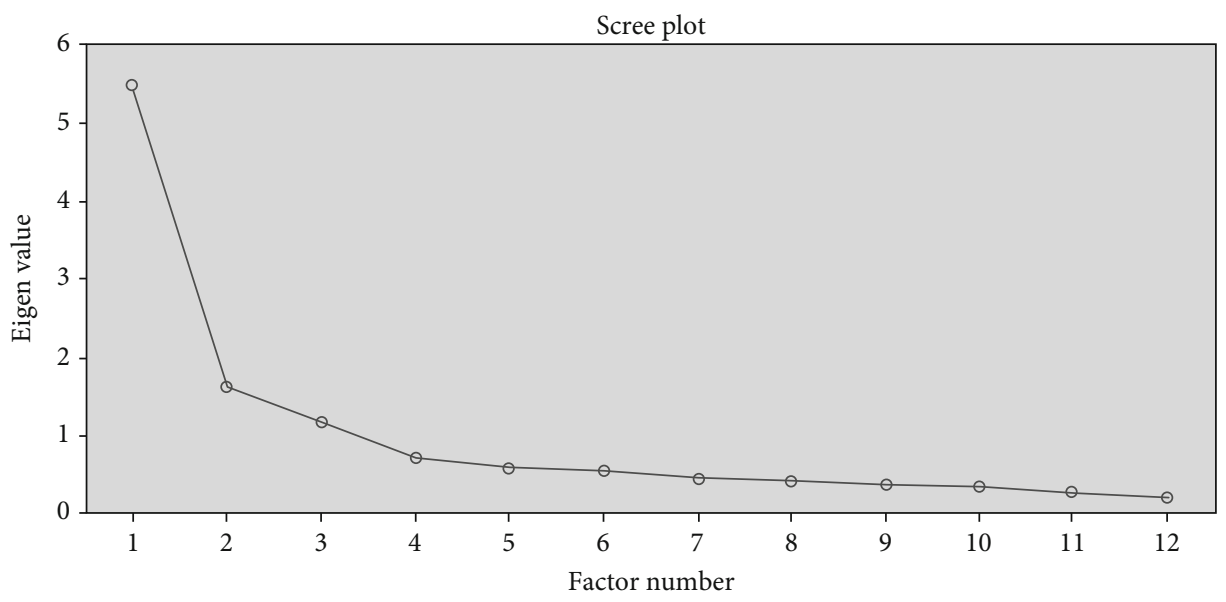

FiguRE 8: Scree plot.

TABLE 11: KMO and Bartlett test.

\begin{tabular}{lcc}
\hline Kaiser-Meyer-Olkin measure of sampling adequacy & 0.860 \\
\hline & Approx. chi square & 3103.525 \\
Bartlett's test of sphericity & Df & 66 \\
& Sig. & 0.000 \\
\hline
\end{tabular}

find the relationship between variables and provides in-depth and complex estimation of the relationship between variables. In view of the above discussion, regression analysis supports comparison of results and used in similar research. Therefore, in this study, it is also used.

Table 17 presents the regression analysis of the dependent variable Wi-Fi-BCD and independent variables (SM). The result shows that independent variables (SM) affect Wi-Fi-BCD positively. The table further explains that the predictor SM (beta $=0.794$ ) best predicts the outcome $\mathrm{Wi}$ Fi-BCD and has a high effect on the dependent variable (Wi-Fi-BCD).

\section{Discussion}

From the above descriptive analysis, Wi-Fi-BCDs affect students' motivation. Based on the observations of the respondents, the Wi-Fi-BCD enhances individual experience, develops digital skills to access ICT services, and makes learning fun. Moreover, the Wi-Fi-BCD enhances student interest and motivates them to learn new things. The majority of the students take interest in interacting with $\mathrm{Wi}-\mathrm{Fi}$ $B C D$ via a tablet computer.

From the inferential statistical analysis, the regression result shows that independent variables (SM) affect Wi-FiBCD positively $(S M$, beta $=0.794) \mathrm{b}$, which shows a high effect on the dependent variable (Wi-Fi-BCD).

The majority of the government globally invests a huge amount in ICT to improve teaching and learning in schools $[8,56]$ suggesting that teachers can make their lessons moti- vating and enriching, with the help of easy access to digital materials. The Wi-Fi-BCD provides easy access to digital materials for teachers and students. The main state in the United Nations (US) formed a one-to-one laptop environment for 5,000 teachers and over 42,000 middle school students.

A survey was conducted to gather information about teachers' use of the laptops and to know teachers' perceptions of their students' use of laptops. About $80 \%$ of the teachers stated that students are more actively engaged and involved in learning new things for high-quality work when using laptops. Students' motivation and class participation improved by using ICT, and the same were confirmed by both the principal and teachers [57].

The teachers and students also affirm that Wi-Fi-BCD increases student motivation. According to DfES (2003) (Department for Education and Skills, United Kingdom), research projects find that ICT plays a major role in students' motivation and encourages them to learn new things, inside and outside the classroom. The path relationship of Wi-FiBCD with SM is tested and found significant positive. The findings of the Wi-Fi-BCD are in line with findings of previous research; thus, it is concluded that the $\mathrm{Wi}-\mathrm{Fi}-\mathrm{BCD}$ improves student motivations.

6.1. Research Question \#3. Is there any significant correlation relationship between Wi-Fi-BCD, SM, PC, PI, PU, PEOU, ATU, and BI contributing to bridging the digital divide?

According to [58], correlation coefficients measure the linear relationship between two or more variables. It also measures the strength and direction of the relationship between variables. It shows the range of association or dependence between variables. The correlation coefficient value $(r)$ ranges from +1 to -1 ; zero means no relationship between variables. The negative value means the opposite relationship between variables if one increases and the other decreases. A positive correlation means that both the variables move in the same direction. If one of the variables increases, the other also increases. 
TABLE 12: EFA correlation matrix.

\begin{tabular}{|c|c|c|c|c|c|c|c|c|c|c|c|c|}
\hline & PEOU1 & PEOU2 & PEOU3 & PEOU4 & PU1 & PU2 & PU3 & PU4 & ATU1 & ATU2 & BI1 & $\mathrm{BI} 2$ \\
\hline PEOU1 & 1 & & & & & & & & & & & \\
\hline PEOU2 & 0.506 & 1 & & & & & & & & & & \\
\hline PEOU3 & 511 & 0.609 & 1 & & & & & & & & & \\
\hline PEOU4 & 0.550 & 0.436 & 0.439 & 11 & & & & & & & & \\
\hline PU1 & 0.380 & 0.278 & 0.317 & 0.394 & 1 & & & & & & & \\
\hline PU2 & 0.203 & 0.351 & 0.327 & 0.228 & 0.518 & 1 & & & & & & \\
\hline PU3 & 0.273 & 0.259 & 0.362 & 0.248 & 0.497 & 0.565 & 1 & & & & & \\
\hline PU4 & 0.328 & 0.265 & 0.234 & 0.356 & 0.559 & 0.423 & 0.453 & 1 & & & & \\
\hline ATU1 & 0.322 & 0.533 & 0.445 & 0.281 & 0.275 & 0.387 & 0.377 & 0.279 & 1 & & & \\
\hline ATU2 & 0.337 & 0.455 & 0.484 & 0.283 & 0.260 & 0.371 & 0.349 & 0.207 & 0.678 & 1 & & \\
\hline BI1 & 0.334 & 0.339 & 0.328 & 0.295 & 0.484 & 0.500 & 0.674 & 0.525 & 0.408 & 0.435 & 1 & \\
\hline $\mathrm{BI} 2$ & 0.367 & 0.312 & 0.294 & 0.375 & 0.520 & 0.443 & 0.481 & 0.759 & 0.339 & 0.290 & 0.643 & 1 \\
\hline
\end{tabular}

TABLE 13: EFA communalities.

\begin{tabular}{lcc}
\hline Variable & Initial & Extraction \\
\hline PEOU1 & 0.454 & 0.582 \\
PEOU2 & 0.521 & 0.577 \\
PEOU3 & 0.498 & 0.551 \\
PEOU4 & 0.391 & 0.499 \\
PU1 & 0.475 & 0.498 \\
PU2 & 0.459 & 0.469 \\
PU3 & 0.559 & 0.558 \\
PU4 & 0.621 & 0.652 \\
ATU1 & 0.544 & 0.607 \\
ATU2 & 0.53 & 0.615 \\
BI1 & 0.618 & 0.638 \\
BI2 & 0.668 & 0.676 \\
\hline
\end{tabular}

TABLE 14: Factor loading matrix.

\begin{tabular}{lccccc}
\hline \multirow{2}{*}{ Item } & \multicolumn{5}{c}{ Factor } \\
& PEOU & PU & ATU & BI & Cronbach alpha \\
\hline PEOU1 & 0.599 & & & & \\
PEOU2 & 0.627 & & & & 0.806 \\
PEOU3 & 0.625 & & & & \\
PEOU4 & 0.560 & & & \\
PU1 & & 0.648 & & & \\
PU2 & & 0.626 & & & \\
PU3 & & 0.668 & & & 0.807 \\
PU4 & & 0.662 & & & \\
ATU1 & & & 0.634 & & 0.783 \\
ATU2 & & & 0.612 & & \\
B11 & & & & 0.735 & \\
B12 & & & & 0.721 & \\
\hline
\end{tabular}

TABle 15: Descriptive statistics.

\begin{tabular}{lcc}
\hline Variable & $\begin{array}{c}\text { Exploratory factor analysis } \\
\text { Mean }\end{array}$ & Std. deviation \\
\hline PEOU1 & 4.16 & 1.058 \\
PEOU2 & 3.92 & 1.007 \\
PEOU3 & 3.9 & 1.066 \\
PEOU4 & 4.07 & 0.962 \\
PU1 & 3.93 & 1.047 \\
PU2 & 3.80 & 1.051 \\
PU3 & 3.81 & 1.102 \\
PU4 & 3.95 & 1.101 \\
ATU1 & 3.74 & 0.969 \\
ATU2 & 3.63 & 1.034 \\
BI1 & 4.18 & 0.959 \\
BI2 & 4.22 & 0.960 \\
\hline
\end{tabular}

To find out the correlation significance between $\mathrm{Wi}$-FiBCD, SM, PC, PI, PEOU, PU, ATU, and BI, Pearson's correlation coefficient is used.

According to $[54,59]$, a correlation range of $r= \pm 0.1$ \pm 0.29 is considered small effect, a range of correlation $r=$ $\pm 0.30- \pm 0.49$ is considered moderate, while $r= \pm 0.50- \pm 1.0$ is considered high.

6.2. Discussion. According to [19, 30], PEOU and PU have been presented to be the key factors of information technology acceptance and usage. According to [60] in their studies using the TAM model, it emphasized a positive relationship between PEOU and PU $[30,60]$, suggesting that PU has effect on BI. According to [46] finding, PU directly positively affects teacher's behavior and intention to use technology.

According to $[19,30]$, the most commonly acknowledged factors of the TAM model are PEOU, PU, and ATU; the PEOU and PU are independent variables to predict the ATU. 
TABLE 16: Wi-Fi-BCD improves student motivation.

\begin{tabular}{lccccc}
\hline Statement & Response & Freq & \% age & Mean & Std. div \\
\hline & Strongly disagree & 23 & 4.4 & & \\
Learning becomes fun & Disagree & 32 & 6.1 & & 1.25 \\
& Undecided & 75 & 14.4 & 3.73 & \\
& Agree & 225 & 43.3 & & \\
& Strongly agree & 166 & 31.9 & & 1.29 \\
Enhances student interest & Strongly disagree & 22 & 4.2 & & \\
& Disagree & 48 & 9.2 & & \\
& Undecided & 79 & 15.2 & 3.87 & \\
& Agree & 238 & 45.7 & & \\
& Strongly agree & 134 & 25.7 & & \\
Motivates to learn new things & Strongly disagree & 23 & 4.4 & & \\
& Disagree & 58 & 11.1 & & \\
& Undecided & 62 & 11.9 & 3.72 & \\
& Agree & 229 & 44 & & \\
& Strongly agree & 149 & 28.6 & & \\
& Strongly disagree & 27 & 5.2 & & \\
& Disagree & 30 & 5.8 & \\
Most of the students take interest in using & Undecided & 84 & 16.1 & 3.64 & \\
& Agree & 187 & 35.9 & & \\
& Strongly agree & 187 & 35.9 & \\
\hline
\end{tabular}

Similarly, the PU is an independent variable to predict the $\mathrm{BI}[61,30]$, suggesting that $\mathrm{BI}$ is the main element that decides whether the users will accept and utilize the technology.

Based on the above discussion, Table 18 shows that the correlation between Wi-Fi-BCD and SM is 0.794 with $p \leq$ 0.01 , between Wi-Fi-BCD and practitioner confidence (PC) is $0.821(p \leq 0.01)$, between $\mathrm{Wi}-\mathrm{Fi}-\mathrm{BCD}$ and positive impact on teaching and learning (PI) is $0.807(p \leq 0.01)$, between $\mathrm{Wi}$-Fi-BCD and PEOU is $0.590(p \leq 0.01)$, between Wi-FiBCD and PU is $0.794(p \leq 0.01)$, between Wi-Fi-BCD and ATU is $0.487(p \leq 0.01)$, and between Wi-Fi-BCD and BI is $0.644(p \leq 0.01)$.

The correlation between the major constructs of the TAM model, PEOU, PU, ATU, and BI also shows a significant positive relationship.

Table 18 shows that the correlation between PEOU and PU is $0.470(p \leq 0.01)$, between PEOU and ATU is 0.541 $(p \leq 0.01)$, between PU and ATU is $0.424(p \leq 0.01)$, between $\mathrm{PU}$ and $\mathrm{BI}$ is $0.772(p \leq 0.01)$, and between $\mathrm{ATU}$ and $\mathrm{BI}$ is $0.443(p \leq 0.01)$.

6.3. Path Analysis. As per the modified TAM model for the study, the path relationships set earlier are tested to examine the (positive or negative, strong, or weak) association between the variables. Table 19 displays the results of the path analysis.

Table 19 displays that all paths are strongly positively significant, the Wi-Fi-BCD positively affects its dependent variables, and PEOU, PU, and ATU also affect the depen-
TABLE 17: Regression analysis of Wi-Fi-BCD and SM.

\begin{tabular}{lccccc}
\hline Model & $\begin{array}{c}\text { Unstandardized } \\
\text { coefficients }\end{array}$ & \multicolumn{4}{l}{$\begin{array}{l}\text { Standardized } \\
\text { coefficients }\end{array}$} \\
& $B$ & $\begin{array}{l}\text { Std. } \\
\text { error }\end{array}$ & Beta & & Sig \\
& 1.125 & 0.216 & 0.794 & 5.221 & 0.000 \\
SM & 0.673 & 0.055 & & 12.165 & 0.000 \\
\hline
\end{tabular}

dent variables. It means that the effect of Wi-Fi-BCD is significantly positive for bridging the digital divide. As per the above findings, the result is in line with previous studies [17-19, 60, 61].

The easiness and acceptance of Wi-Fi-BCD positively affect the PEOU and PU. Similarly, the PEOU positively affects the PU. The PEOU and PU as independent variables positively predict the dependent variable ATU. The PU is an independent variable for the BI, positively affecting the BI. Similarly, the independent variable ATU for BI also predicts the dependent variable $\mathrm{BI}$.

The ATU is the use of the Wi-Fi-BCD. The research is in line with the previous research of [62]. Based on the above discussion, it is concluded that the PEOU and PU of the Wi-Fi-BCD are positively correlated with the Wi-Fi-BCD. It shows that the students and teachers found the Wi-FiBCD easy and useful. Similarly, the correlation between PEOU and PU positively correlates with the ATU; it shows the attitude towards using the Wi-Fi-BCD by teachers and students. The ease of use of the system affects the users to make positive ATU of that system [30]. 
TABLE 18: Pearson correlation matrix.

\begin{tabular}{|c|c|c|c|c|c|c|c|c|}
\hline & Wi-Fi-BCD & SM & $\mathrm{PC}$ & PI & PEOU & $\mathrm{PU}$ & ATU & $\mathrm{BI}$ \\
\hline Wi-Fi-BCD & 1 & & & & & & & \\
\hline SM & $0.794^{* *}$ & 1 & & & & & & \\
\hline $\mathrm{PC}$ & $0.821^{* *}$ & $0.430^{* *}$ & 1 & & & & & \\
\hline PI & $0.807^{* *}$ & $0.967^{* *}$ & $0.826^{* *}$ & 1 & & & & \\
\hline PEOU & $0.590^{* *}$ & $0.470^{* *}$ & $0.309^{* *}$ & $0.333^{* *}$ & 1 & & & \\
\hline $\mathrm{PU}$ & $0.794^{* *}$ & $1.000^{* *}$ & $0.430^{* *}$ & $0.967^{* *}$ & $0.470^{* *}$ & 1 & & \\
\hline ATU & $0.487^{* *}$ & $0.424^{* *}$ & $0.300^{* *}$ & $0.400^{* *}$ & $0.541^{* *}$ & $0.424^{* *}$ & 1 & \\
\hline $\mathrm{BI}$ & $0.644^{* *}$ & $0.772^{* *}$ & $0.453^{* *}$ & $0.726^{* *}$ & $0.458^{* *}$ & $0.772^{* *}$ & $0.443^{* *}$ & 1 \\
\hline
\end{tabular}

TABLE 19: Path analysis of modified TAM model.

\begin{tabular}{lcccc}
\hline $\begin{array}{l}\text { Dependent } \\
\text { variable }\end{array}$ & $\begin{array}{c}\text { Independent } \\
\text { variable }\end{array}$ & $r$ & $P$ & Test \\
\hline Wi-Fi-BCD & SM & 0.794 & 0.000 & Positively significant \\
Wi-Fi-BCD & PC & 0.821 & 0.000 & Positively significant \\
Wi-Fi-BCD & PI & 0.807 & 0.000 & Positively significant \\
Wi-Fi-BCD & PEOU & 0.590 & 0.000 & Positively significant \\
Wi-Fi-BCD & PU & 0.794 & 0.000 & Positively significant \\
PEOU & PU & 0.740 & 0.000 & Positively significant \\
PEOU & ATU & 0.541 & 0.000 & Positively significant \\
PU & ATU & 0.424 & 0.000 & Positively significant \\
ATU & BI & 0.443 & 0.000 & Positively significant \\
\hline
\end{tabular}

\section{Conclusion and Future Work}

This research investigated the effects of Wi-Fi-BCD to bridge the digital divide in Government Girls Secondary and Higher Secondary Schools of Chitral. The project of Wi-Fi-BCD provides facilities for female students in Chitral to use ICT and to get hands-on experience in the field. The Wi-Fi-BCD is developed for the Government Girls Secondary and Higher Secondary School of Chitral to provide ICT facilities successfully. The modified TAM model is used to find the effects of Wi-Fi-BCD for bridging the digital divide. The path relationship is found significantly positive. The effects of Wi-Fi-BCD on student's motivation, practitioner confidence, teaching, and learning are meaningfully positive. The effects of Wi-Fi-BCD on its PEOU and PU are found pointedly positive. The PEOU and PU positively affect the ATU; this indicates that the Wi-Fi-BCD is easy to use and it is useful. The ATU positively affects the BI; this indicates the actual usage of the $\mathrm{Wi}-\mathrm{Fi}-\mathrm{BCD}$. The results of this research show that $\mathrm{Wi}-\mathrm{Fi}-$ $\mathrm{BCD}$ has quite positive effects on bridging the digital divide. The teachers agree that the use of Wi-Fi-BCD is applicable in practical situations, and it may help the female learners in the field of ICT. Future research may include developing local language contents in Wi-Fi-BCD to remove the language barriers from the subject of content distributor.

\section{Data Availability}

The data collected during the data collection phase will be provided upon request to the authors.

\section{Conflicts of Interest}

The authors declare no potential conflict of interests.

\section{Acknowledgments}

The work presented in this paper was supported by the China University of Petroleum-Beijing, Fundamental Research Funds for the Central Universities under Grant number 2462020YJRC001. The authors also acknowledge the support provided by Prof. Dr. Khan Bahadar Marwat (SI) and Prof. Dr. Lutfullah Kakakhel throughout the execution of this project.

\section{References}

[1] A. Zafar, "Woes of primary education in Khyber Pakhtunkhwa," 2018, https://chitraltoday.net/2018/02/15/woesof-primary-education-in-khyber-pakhtunkhwa/.

[2] K. Waqas, "ICT in education, reached? Nowhere!," 2018, https://archive.pakistantoday.com.pk/2017/06/18/ict-ineducation-reached-nowhere/.

[3] Report, "Annual Statistical Report Government Schools 201415," 2016, http://library.aepam.edu.pk.

[4] ASER, Annual Status of Education Report: ASER Pakistan 2015 National (Urban), Federal Ministry of Education, Pakistan, 2015.

[5] Statistic Pakistan, Annual Statistical Report Government Schools, Department of Elementary \& Secondary Education, Khyber Pakhtunkhwa, Pakistan, 2015.

[6] CIDA, CIDA Strategy on Knowledge for Development through ICT, Canadian International Development Agency, 2006.

[7] M. O. Yusuf, "Information and communication technology and education: analysing the Nigerian national policy for information technology," International Education Journal, vol. 6, no. 3, pp. 316-321, 2005.

[8] C. Buabeng-Andoh, "Factors influencing teachersâ adoption and integration of information and communication technology into teaching: a review of the literature," International 
Journal of Education and Development using ICT, vol. 8, no. 1, 2012.

[9] M. Andrade-Aréchiga, G. López, and G. López-Morteo, "Assessing effectiveness of learning units under the teaching unit model in an undergraduate mathematics course," Computers \& Education, vol. 59, no. 2, pp. 594-606, 2012.

[10] R. J. Khobo, The effect of using computers for the teaching and learning of Mathematics to grade 10 learners at secondary school, [M.S. thesis], University of South Africa, Pretoria, South Africa, 2015.

[11] M. Marshman and P. Grootenboer, "Scissors, papers rock: old-world technologies for future-proofing pedagogy. Reengaging students in mathematics classrooms," in Transformative Approaches to New Technologies and Student Diversity in Futures Oriented Classrooms, pp. 139-158, Springer, 2012.

[12] OECD, "Organization for economic co-operation and development," 2001, http://www.oecd.org/dataoecd.

[13] H. Ono and M. Zavodny, "Digital inequality: a five country comparison using microdata," Social Science Research, vol. 36, no. 3, pp. 1135-1155, 2007.

[14] J. Van Dijk and K. Hacker, "The digital divide as a complex and dynamic phenomenon," The Information Society, vol. 19, no. 4, pp. 315-326, 2003.

[15] J. A. Van Dijk, "Digital divide: impact of access," The International Encyclopedia of Media Effects, vol. 1, pp. 1-11, 2017.

[16] J. P. Shim, M. Warkentin, J. F. Courtney, D. J. Power, R. Sharda, and C. Carlsson, "Past, present, and future of decision support technology," Decision Support Systems, vol. 33, no. 2, pp. 111-126, 2002.

[17] R. J. Vallerand, P. Deshaies, J.-P. Cuerrier, L. G. Pelletier, and C. Mongeau, "Ajzen and Fishbein's theory of reasoned action as applied to moral behavior: a confirmatory analysis," Journal of Personality and Social Psychology, vol. 62, no. 1, pp. 98-109, 1992.

[18] V. Venkatesh, M. G. Morris, G. B. Davis, and F. D. Davis, "User acceptance of information technology: toward a unified view," MIS Quarterly, vol. 27, no. 3, pp. 425-478, 2003.

[19] F. D. Davis, R. P. Bagozzi, and P. R. Warshaw, "User acceptance of computer technology: a comparison of two theoretical models," Management Science, vol. 35, no. 8, pp. 982-1003, 1989.

[20] P. Legris, J. Ingham, and P. Collerette, "Why do people use information technology? A critical review of the technology acceptance model," Information \& Management, vol. 40, no. 3, pp. 191-204, 2003.

[21] D. W. Turner III, "Qualitative interview design: a practical guide for novice investigators," The Qualitative Report, vol. 15, no. 3, pp. 754-760, 2010.

[22] J.-H. Wu and S.-C. Wang, "What drives mobile commerce?: an empirical evaluation of the revised technology acceptance model," Information \& Management, vol. 42, no. 5, pp. 719729, 2005.

[23] S. R. Hill and I. Troshani, "Adoption of personalisation mobile services: evidence from young Australians,” BLED 2009 Proceedings, vol. 35, 2009.

[24] Y. Lee and K. A. Kozar, "The technology acceptance model: past, present, and future," Larsen, pp. 752-780, 2003.

[25] K. Mathieson, "Predicting user intentions: comparing the technology acceptance model with the theory of planned behavior," Information Systems Research, vol. 2, no. 3, pp. 173-191, 1991.
[26] A. N. Luhamya, F. E. K. Bakkabulindi, and P. B. Muyinda, "Using the theory of planned behaviour to explain the integration of ICT in teaching and learning by educators in public teacher training colleges in Tanzania," International Journal of Computing \& ICT Research, vol. 11, no. 2, 2017.

[27] J. A. G. M. van Dijk, O. Peters, and W. Ebbers, "Explaining the acceptance and use of government Internet services: a multivariate analysis of 2006 survey data in the Netherlands," Government Information Quarterly, vol. 25, no. 3, pp. 379-399, 2008.

[28] S. Järvelä, "Shifting research on motivation and cognition to an integrated approach on learning and motivation in context," Motivation in learning contexts: Theoretical advances and methodological implications, pp. 3-14, 2001.

[29] P. A. Ertmer and A. T. Ottenbreit-Leftwich, "Teacher technology change," Journal of research on Technology in Education, vol. 42, no. 3, pp. 255-284, 2010.

[30] V. Venkatesh and M. G. Morris, “Why don't men ever stop to ask for directions? Gender, social influence, and their role in technology acceptance and usage behavior," MIS Quarterly, vol. 24, no. 1, pp. 115-139, 2000.

[31] S. Taylor and P. A. Todd, "Understanding information technology usage: a test of competing models," Information Systems Research, vol. 6, no. 2, pp. 144-176, 1995.

[32] N. Jahangir and N. Begum, "The role of perceived usefulness, perceived ease of use, security and privacy, and customer attitude to engender customer adaptation in the context of electronic banking," African Journal of Business Management, vol. 2, no. 2, pp. 032-040, 2008.

[33] H. Amin, "Internet banking adoption among young intellectuals," The Journal of Internet Banking and Commerce, vol. 12, no. 3, pp. 1-13, 1970.

[34] M. Leonard, S. Graham, and D. Bonacum, "The human factor: the critical importance of effective teamwork and communication in providing safe care," BMJ Quality \& Safety, vol. 13, Supplement 1, pp. 85-90, 2004.

[35] M. N. K. Saunders and P. Lewis, Doing Research in Business \& Management: An Essential Guide to Planning your Project, Pearson, 2012.

[36] N. Malhotra and D. Birks, Marketing Research: An Applied Approach: 3rd European Edition, Pearson Education, 2007.

[37] J. H. McMillan and S. Schumacher, Research in Education: Evidence-Based Inquiry, MyEducationLab Series, Pearson, 2010.

[38] R. K. Yin, "The case study crisis: some answers," Administrative Science Quarterly, vol. 26, no. 1, pp. 58-65, 1981.

[39] H. C. J. Godfray, J. R. Beddington, I. R. Crute et al., "Food security: the challenge of feeding 9 billion people," Science, vol. 327, no. 5967, pp. 812-818, 2010.

[40] L. R. Gay, G. E. Mills, and P. Airasian, Educational Research: Competencies for Analysis and Application, Pearson, 4th edition, 1992.

[41] N. J. Kathuri and D. A. Pals, Introduction to Educational Research, Scientific Research Publishing, Njoro Kenya, 1993.

[42] Y. P. Chua, Research Method, McGraw-Hill Companies, Malaysia, 2011.

[43] O. M. Mugenda and A. G. Mugenda, Qualitative and quantitative approaches, Research Methods Africa Center for Technology Studies (Acts) Press, Nairobi Kenya, 2003. 
[44] J. F. Hair, W. C. Black, B. J. Babin, R. E. Anderson, and R. L. Tatham, Análise multivariada de dados, Bookman Editora, 2009.

[45] C. Marshall and G. B. Rossman, "The "what" of the study: building the conceptual framework," Designing Qualitative Research, vol. 3, no. 3, pp. 21-54, 1999.

[46] T. Teo, Technology Acceptance Research in Education, Springer, 2011.

[47] F. Yaghmaie, "Content validity and its estimation," Journal of Medical Education, vol. 3, no. 1, 2003.

[48] M. R. Lynn, "Determination and quantification of content validity," Nursing Research, vol. 35, no. 6, 1986.

[49] D. F. Polit, C. T. Beck, and S. V. Owen, "Is the CVI an acceptable indicator of content validity? Appraisal and recommendations," Research in Nursing \& Health, vol. 30, no. 4, pp. 459-467, 2007.

[50] A. M. Farrell and J. M. Rudd, "Factor analysis and discriminant validity: a brief review of some practical issues," in Australia-New Zealand Marketing Academy Conference, Australia-New Zealand Marketing Academy, 2009.

[51] S. M. Fox-Wasylyshyn and M. M. El-Masri, "Handling missing data in self-report measures," Research in Nursing \& Health, vol. 28, no. 6, pp. 488-495, 2005.

[52] Y. Akbulut, S. Şendağ, G. Birinci, K. Kılıçer, M. C. Şahin, and H. F. Odabaşı, "Exploring the types and reasons of Internettriggered academic dishonesty among Turkish undergraduate students: development of Internet-triggered academic dishonesty scale (ITADS)," Computers \& Education, vol. 51, no. 1, pp. 463-473, 2008.

[53] B. Norman, Analyzing Quantitative Data: From Description to Explanation, Sage, 2003.

[54] J. Pallant, SPSS Survival Manual: A Step by Step Guide to Using SPSS for Windows (Version 12), Allen \& Unwin, New SouthWales, Australia, 2005.

[55] N. Opitz, T. F. Langkau, N. H. Schmidt, and L. M. Kolbe, “Technology acceptance of cloud computing: empirical evidence from German IT departments," in 2012 45th Hawaii International Conference on System Sciences, Maui, HI, USA, 2012.

[56] A. Balanskat, R. Blamire, and S. Kefala, The ICT Impact Report: A Review of Studies of ICT Impact on Schools in Europe, European Communities, 2006.

[57] D. L. Silvernail and D. M. M. Lane, The Impact of MaineâĂŹs One-to-One Laptop Program on Middle School Teachers and Students, Maine Education Policy Research Institute (MEPRI), University of Southern Maine, 2004.

[58] B. G. Tabachnick and L. S. Fidell, "Principal components and factor analysis," Using Multivariate Statistics, vol. 4, pp. 582633, 2001.

[59] J. Cohen, Statistical Power Analysis for the Behavioral Sciences, Routledge, 2013.

[60] H. Van der Heijden, "Factors influencing the usage of websites: the case of a generic portal in The Netherlands," Information \& Management, vol. 40, no. 6, pp. 541-549, 2003.

[61] K. McKinnon and A. Igonor, "Explaining eLearning perceptions using the technology acceptance model and the theory of planned behavior," in Proceedings of E-Learn 2008-World Conference on E-Learning in Corporate, Government, Healthcare, and Higher Education, Las Vegas, Nevada, USA, 2008.

[62] M. Kim, M. Park, and D. Jeong, "The effects of customer satisfaction and switching barrier on customer loyalty in Korean mobile telecommunication services," Telecommunications Policy, vol. 28, no. 2, pp. 145-159, 2004. 